\title{
O Processo de Implantação do Balanced Scorecard na Gestão Estratégica de uma Pequena Empresa Prestadora de Serviços
}

\author{
Bárbara Gonçalves do Amaral $^{1}$, Sérgio Murilo Petri ${ }^{1}$, Josiane Marostica ${ }^{1}$ \\ ${ }^{1}$ Universidade Federal de Santa Catarina- UFSC \\ e-mail de contato: sergio.petri@ufsc.br
}

Resumo

O presente artigo tem como intuito implantar um Balanced Scorecard (BSC) para uma pequena empresa prestadora de serviços de segurança privada, constatando as contribuições desse sistema de gestão estratégico como ferramenta auxiliar no desempenho da organização. Devido à existência premente de aplicação de medidas de desempenho não mais direcionada ao controle, entretanto focalizadas na visão estratégica optou-se por um método que busca traduzir a visão estratégica empresarial. Para alcançar tal objetivo, adotou-se por base o planejamento estratégico da empresa realizado em 2014/2015. Nesse sentido, a sustentação metodológica para se constituir o melhor direcionamento a ser seguido pela empresa deu-se na composição administrativa do planejamento estratégico. Vale ressaltar, que foram necessários alguns ajustes no plano existente, a fim de assegurar maior veracidade a realidade da empresa para iniciação do Balanced Scorecard.

Palavras-chaves:Balanced Scorecard; Pequenas empresas; Segurança Privada,Gestão Estratégica; Planejamento Estratégico; Indicadores.

\begin{abstract}
This article has the intention to implement a Balanced Scorecard (BSC) for a small company providing private security, nothing the contributions of this strategic management system as an auxiliary tool in the performance of the organization. Due to the existence of urgent application of performance measures no longer directed to the control, however focused on the strategic vision we chose a method that seeks to translate the strategic business vision. To achieve this goal, it adopted based on the strategic planning carried out in 2014/2015. In this sense, the methodological support to be the best direction to be followed by the company was given the administrative composition of strategic planning. It is noteworthy that some adjustments were necessary in the existing plan, to ensure greater truth of the reality of the company to start the Balanced Scorecard.
\end{abstract}

Keywords: Balanced Scorecard; Small business; Private Security, Strategic Management; Strategic planning; Indicators.

\section{Introdução}

Atualmente, as entidades vivenciam uma série de mudanças, carecendo de controles eficazes e de informes oportunos referente aos seus negócios para adequar suas operações às novas situações de mercado. Como exemplo de possíveis mudanças, conforme o Serviço Brasileiro de Apoio às Micro e Pequenas Empresas (SEBRAE) a Lei Complementar 147/2014 a qual vigora em 2015 aprova o Super simples, um sistema de tributação que unifica oito impostos tanto federais, estaduais ou municipais para 


\section{REAVI}

Universidade do Estado de Santa Catarina

Centro de Educação Superior do Alto Vale do Itajaí

único pagamento, reduzindo em média $40 \%$ de carga tributária especificamente para as micros e pequenas empresas.

Com isso vem a beneficiar 140 novas categorias, uma vez que prevalece o faturamento e o porte de adesão da entidade e não a atividade exercida, enfocando em diversos trabalhadores na área de serviço quais podem pagar menos tributos no Supersimples. Nesta linha pense: mesmo que uma empresa de pequeno porte entre no mercado e adote tal forma de tributação, reduzindo a capacidade de carga tributária, sua permanência no mercado pelo planejamento independente da situação favorável de sua abertura. Pois, há diversos fatores que contribuem para continuidade de uma empresa.

Assim, no decorrer dos tempos, diversos foram os instrumentos desenvolvidos para planejar, controlar e organizar os empreendimentos, na busca do melhor molde de gerência. Desta forma, os informes gerenciais são de suma importância para a avaliação do desempenho organizacional.

Observa-se que as micro e pequenas entidades normalmente são administradas pelos próprios societários, os quais detém capacitação técnica relacionada ao seu negócio, contudo ausência de capacitação administrativa em gestão, por exemplo marketing, contabilidade, finanças, entre outros. Desta forma, são pouquíssimas as entidades de pequeno porte que cursam seu sexto ano de vida, gerando um cenário com futuras falências, recuperações judiciais e desempregos. Devido, a deficiência de conhecimento da gestão diária, a omissão do planejamento e orçamento prévio do negócio, etc.

É fundamental esclarecer que as entidades que empregam um sistema integrado de contabilidade gerencial têm um diferencial positivo em relação às que não têm. Portanto, os informes gerenciais, analisados em financeiro ou não financeiro, tornam-se essenciais na medida em que os gestores situarem tanto os ensejos quanto às ameaças do ambiente/mercado às entidades.

A maioria das entidades visa somente indicadores financeiros ou indicadores não financeiros, logo na ausência de uma visão ampla tem-se a lucratividade em curto prazo como supervalorizada, o que dificulta o crescimento de certos fatores, já que investimentos de retorno em longo prazo não são priorizados.

Além disso, sempre que incide determinada variação na concorrência, as entidades precisam reconsiderar como os informes irão afetar seu desempenho em longo prazo, levando as entidades a terem uma missão e estratégia empresarial em um sistema 


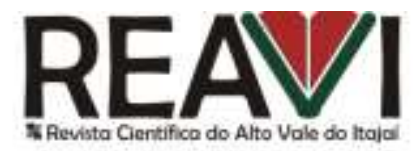

Universidade do Estado de Santa Catarina

Centro de Educação Superior do Alto Vale do Itajaí

que transmite na prática a intenção estratégica, e direcionando o desempenho para os desígnios instituídos.

Desta forma, há a necessidade de equilíbrio entre os objetivos de curto e longo prazo, entre as medidas financeiras e não financeiras e também entre as perspectivas internas e externas de desempenho para as tomadas de decisões e medidas de desempenho.

Kaplan e Norton(1999), reportam que o Balanced Scorecard (BSC) tornou-se um dos sistemas de avaliação desempenho com a capacidade de gerenciar a estratégia das entidades e de ter tal equilíbrio, cuja estrutura é bastante aplicada hoje em dia.

Neste sentido o presente artigo tem como propósito implantar o Balanced Scorecard em uma pequena empresa prestadora de serviço no ramo de segurança privada, tendo como pergunta de pesquisa: Quais as contribuições do processo de implantação do Balanced Scorecard para uma empresa de pequeno porte? A partir do apresentado, tem-se como justificativa identificar o Balanced Scorecard como ferramenta ligada à organização estrutural da gestão estratégia numa empresa de pequeno porte, permitindo focar nas perspectivas estimadas e a verificação do gerenciamento em toda a empresa em variáveis capazes de agir diretamente e indiretamente nas ações dela, auxiliando na execução do planejamento estratégico já existente.

\section{Referencial teórico}

Nesta seção, será discorrido e contestado o BSC como ferramenta de contribuição a gestão estratégica, além de pesquisas análogas que auxiliam o objetivo do presente estudo.

\subsection{Balanced Scorecard}

Em 1992, o primeiro artigo sobre Balanced Scorecard (BSC) foi publicado na Harvard Business Review por autoria de Robert Kaplan e David Norton, intitulado The Balanced Scorecard: Measures that drive performance. Este artigo propôs um conjugado de medidas de desempenho, concedendo aos executivos um horizonte mais abrangente de seu empreendimento que os sistemas de avaliação de desempenho tradicionais. Pode-se interpretar a terminação o Balanced Scorecard como um cartão de 


\section{REAVI}

Universidade do Estado de Santa Catarina

Centro de Educação Superior do Alto Vale do Itajaí

marcação balanceado, portanto uma ferramenta estratégica que objetiva o equilíbrio entre os indicadores de desempenho.

Observa-se que o BSC constitui-se num sistema de gestão estratégica, que deriva da visão e dos objetivos estratégicos da empresa, preservando os indicadores financeiros tradicionais e reconhecendo a construção de ativos intangíveis e capacidades competitivas. Herrero (2005), afirma ser insuficiente medir somente a saúde financeira, sendo necessário verificar a saúde estratégica a longo prazo, assim realizado pelo BSC.

\section{Figura 1: Definindo as relações de causa e efeito da estratégia}

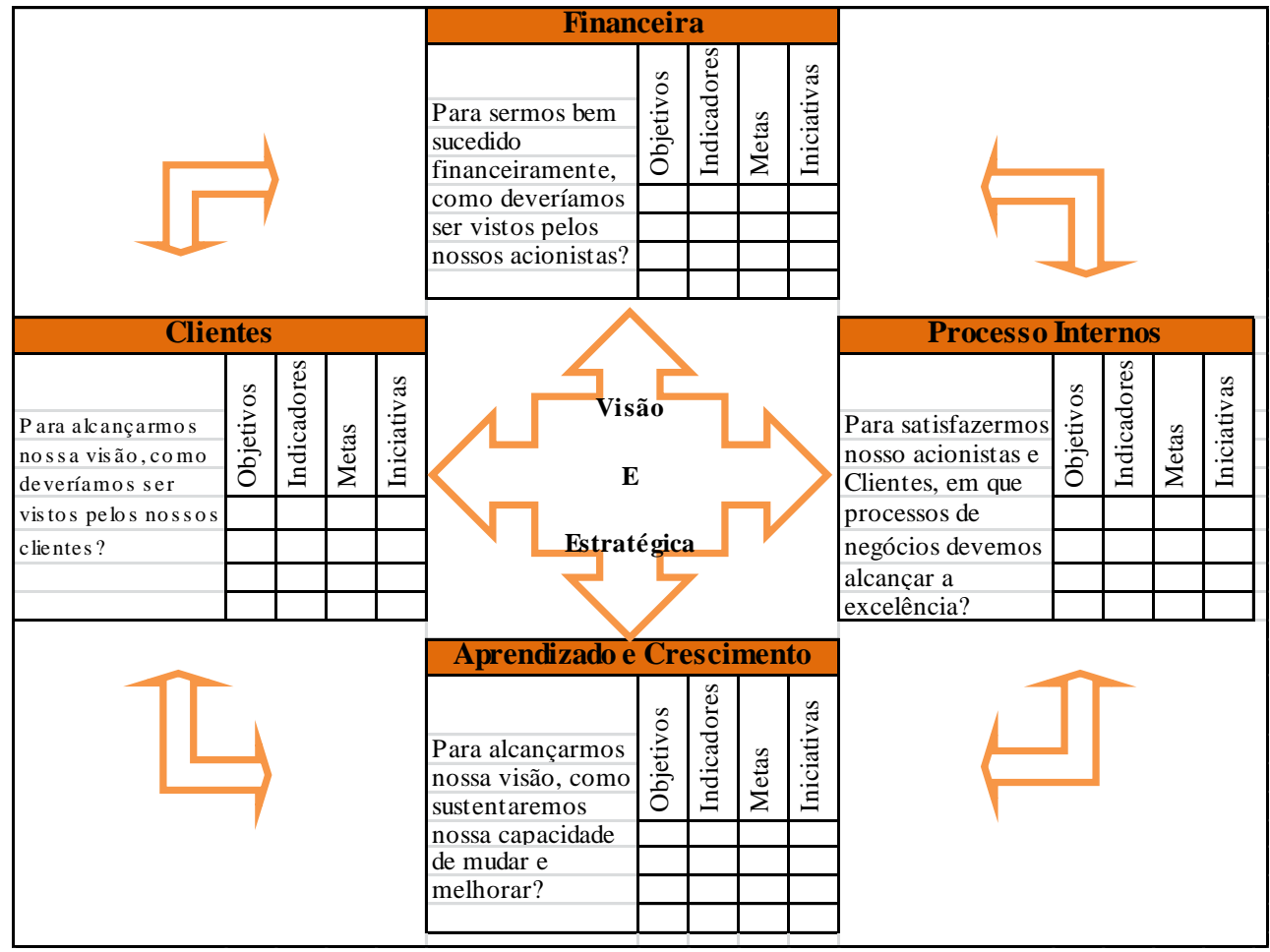

Fonte: Kaplan e Norton $(1997$, p. 10).

Para Vieira (2014), o BSC orienta a empresa a efetuar o planejamento estratégico, de maneira a compor as causas e efeitos nas atividades desenvolvidas e propostas por ela. Neste sentido, Kaplan e Norton alegam que o BSC é complementa as medidas operacionais de satisfação dos clientes, dos processos internos e das atividades relacionadas com a inovação e a aprendizagem organizacional, assim cada uma dessas perspectivas são desenvolvidos indicadores que traduzem a estratégia da alta administração para os níveis estratégico, tático e operacional. Na Figura 1 reflete a visão dos autores.

Nessa linha Soares e Silva (2013) expõem que a exposição da missão e visão objetiva capacitarem as pessoas e os processos para que tenha retenção de clientes, 


\section{REAVI}

Universidade do Estado de Santa Catarina

Centro de Educação Superior do Alto Vale do Itajaí

conquista de novos segmentos de mercado com produtos e serviços inovadores, treinamento de colaboradores visando o atendimento de qualidade, menores custos e incentivar o feedback, contribui para uma melhora contínua.

Sendo assim, Kaplan e Norton (1997, p.20) afirmam que "o verdadeiro poder do Balanced Scorecard, todavia, ocorre quando deixa de ser um sistema de medidas e se transforma em um sistema de gestão estratégica", ou seja, a empresa necessita de indicadores capazes de medir os reflexos do mapa estratégico para avaliar se as metas desejadas são efetivadas.

Desta forma Soares e Silva (2012) mostram dados divulgados pelo Serviço Brasileiro de Apoio às Micro e PequenasEmpresas SEBRAE- (2008):

\footnotetext{
"As pequenas empresas representam 99,2\% das empresas, e sãoresponsáveis por cerca $60 \%$ dos empregos gerados. As pequenas empresas têm um diferencialmuito importante, o proprietário atua diretamente na direção, nas finanças, no processo deprodução e venda de seus produtos, tendo que conhecer a fundo todos os processos utilizadospela empresa."
}

Nota-se que a implantação do BSC nas empresas de pequeno porte carece de uma reestruturação em alguns pontos para esta realidade uma vez que estas não detêm de formalização nas atividades mais rotineiras, tento um BSC de aplicaçãosimples para possível aceitação por todos os colaboradores na empresa.

\subsection{Pesquisas acadêmicas análogas}

A seguir, no Quadro 1, verifica-se a realização de pesquisas acadêmicas análogas ao estudo prestado, visando o avaliação de desempenho por meio do BSC, especificamente em pequenas empresas.

Nas pesquisas acima se ressaltam o artigo de Bernardi, Silva e Batocchio (2013) o qual estabelece um estudo comparativo entre pequenas e grandes empresas. Assim se extrai e se adapta unicamente os fatores relativos às pequenas empresas, visando uma para formação válida ao BSC. Conforme os autores as empresas de pequeno porte devido suas características, são desprovidas de formalidades em alguns processos básicos de gerenciamento, necessitando a implementação do BSC de forma simples, abrangendo um nível de compreensão e aplicabilidade com fácil acesso para todos da empresa.

Ressalta-se que a estrutura presente neste estudo fundamenta-se na pesquisa de desenvolvida por Vieira(2014). No entanto, observam-se alguns diferenciais entre os 


\section{REAVI}

Universidade do Estado de Santa Catarina

Centro de Educação Superior do Alto Vale do Itajaí

trabalhos no processo de análise dos dados como: o autor proporciona uma análise geral abrangendo todas as perspectivas do BSC. Contudo, a análise exposta neste estudo se aplica na perspectiva de clientes, uma vez que há uma necessidade imprescindível pela entidade de maior deferência neste âmbito de gestão estratégica em seu cenário atual, acatando a solicitação da administração. Embora, o presente estudo expresse o painel do BSC completo, evidenciando todas as perspectivas com seus respectivos indicadores de desempenho, status quo e metas extraídas e iniciativas discutidas.

\section{Quadro 1: Pesquisasanteriores sobre BSC}

\begin{tabular}{|c|c|c|c|}
\hline Autores & Objetivo & Resultado & Aspectos relevantes \\
\hline $\begin{array}{l}\text { Drouvot, } \\
\text { Cláudia } \\
\text { Magalhães } \\
\text { Drouvot, Sérgio } \\
\text { Castro Gomes. } \\
(2014)\end{array}$ & $\begin{array}{l}\text { Desenvolver o BSC numa } \\
\text { empresa prestadora de serviços } \\
\text { de contábeis apoiando no } \\
\text { seguinte questionamento: } \\
\text { Quais as contribuições da } \\
\text { elaboração de um BSC para } \\
\text { um escritório de contabilidade? }\end{array}$ & $\begin{array}{l}\text { Conclui-se que essa } \\
\text { ferramenta cumpriu com o } \\
\text { objetivo de apoiar a gestão } \\
\text { estratégica de uma empresa } \\
\text { de pequeno porte e } \\
\text { prestadora de serviços } \\
\text { contábeis. }\end{array}$ & $\begin{array}{l}\text { Na figura } 2 \text { tem-se o gráfico } \\
\text { evidenciando os } 13 \text { objetivos } \\
\text { estratégicos comparando o } \\
\text { estado atual com a meta. Nota- } \\
\text { se que a empresa apresenta uma } \\
\text { meta em nível de excelência. }\end{array}$ \\
\hline $\begin{array}{l}\text { Lima, Gonzaga } \\
\text { e Fehr (2013) }\end{array}$ & $\begin{array}{l}\text { Analisar a implantação do } \\
\text { BSC em uma construtora de } \\
\text { pequeno porte localizada em } \\
\text { Belo Horizonte/MG, } \\
\text { considerando-se a ausência de } \\
\text { alguns dos requisitos descritos } \\
\text { na literatura para a implantação } \\
\text { da ferramenta. }\end{array}$ & $\begin{array}{l}\text { Verificou-se a possível } \\
\text { implantação e utilização do } \\
\text { BSC em empresas de } \\
\text { pequeno porte quando } \\
\text { ponderadas suas } \\
\text { especificidades e } \\
\text { necessidades. }\end{array}$ & $\begin{array}{l}\text { A demarcação de uma figura } \\
\text { como responsável pelo projeto } \\
\text { de implantação e a distribuição } \\
\text { diretrizes estratégicas para } \\
\text { grupos de colaboradores no } \\
\text { setor administrativo da } \\
\text { construtora, minimizou a } \\
\text { sobrecarregar da diretoria geral. }\end{array}$ \\
\hline $\begin{array}{l}\text { Belli, } \\
\text { Andruchechen, } \\
\text { AlbertonePetri } \\
(2013)\end{array}$ & $\begin{array}{l}\text { Aplica-se uma pesquisa-ação } \\
\text { objetivando delinear as etapas } \\
\text { para o processo do } \\
\text { planejamento estratégico e da } \\
\text { implementação do Balanced } \\
\text { Scorecard para uma } \\
\text { microempresa no ramo de } \\
\text { fabricação de tintas e } \\
\text { revestimentos. }\end{array}$ & $\begin{array}{l}\text { O BSC centralizado em uma } \\
\text { microempresa é capaz de } \\
\text { fornecer informações para } \\
\text { apoiar as decisões dos } \\
\text { gestores e nortear o futuro } \\
\text { da empresa. }\end{array}$ & $\begin{array}{l}\text { Os pontos fortes indicam que a } \\
\text { empresa possui capacidade } \\
\text { suficiente para prosperar no } \\
\text { mercado. Mas, se observa que } \\
\text { os pontos fracos estão } \\
\text { estreitamente ligados à falta de } \\
\text { capital para investir na } \\
\text { ampliação da empresa e em } \\
\text { novas tecnologias. }\end{array}$ \\
\hline $\begin{array}{l}\text { Bernardi, Silva } \\
\text { e Batocchio } \\
(2012)\end{array}$ & $\begin{array}{l}\text { Apresentar um estudo de caso } \\
\text { que demonstre os resultados } \\
\text { positivos dos indicadores de } \\
\text { desempenho por meio do BSC } \\
\text { nas micros e pequenas } \\
\text { empresas. }\end{array}$ & $\begin{array}{l}\text { A implantação do BSC } \\
\text { apontou melhorias tanto nos } \\
\text { aspectos financeiros } \\
\text { (exemplo: margem de } \\
\text { contribuição) quanto não } \\
\text { financeiro (exemplo: } \\
\text { pontualidades nas entregas } \\
\text { das mercadorias). }\end{array}$ & $\begin{array}{l}\text { O presente estudo determinou } \\
\text { uma pesquisa survey descritiva } \\
\text { com a população total da } \\
\text { empresa. Além de compor três } \\
\text { questionários para coleta de } \\
\text { dados, estando dois como não } \\
\text { estruturado e não disfarçado e, } \\
\text { um estruturado e não } \\
\text { disfarçado. }\end{array}$ \\
\hline
\end{tabular}




\begin{tabular}{|c|c|c|c|}
\hline $\begin{array}{l}\text { Cimini e } \\
\text { Silveira (2008) }\end{array}$ & $\begin{array}{l}\text { Apoia-se na possibilidade de } \\
\text { implantação do BSC em } \\
\text { pequenas empresas, a partir de } \\
\text { um estudo sobre as } \\
\text { caraterísticas de empresas de } \\
\text { pequeno porte. }\end{array}$ & $\begin{array}{l}\text { De acordo com os autores o } \\
\text { BSC permite ser uma fonte } \\
\text { de melhoria na gestão } \\
\text { estratégica empresarial, caso } \\
\text { detenha os objetivos } \\
\text { estratégicos, indicadores e } \\
\text { direcionadores alinhados } \\
\text { corretamente com as metas. }\end{array}$ & $\begin{array}{l}\text { A conscientização progressiva } \\
\text { em uma pequena empresa é } \\
\text { uma forma motivacional de } \\
\text { envolver os colaboradores entre } \\
\text { seus diversos setores, uma vez } \\
\text { que a dinâmica interna é } \\
\text { essencial para as pequenas } \\
\text { empresas se adaptarem às } \\
\text { exigências do mercado. }\end{array}$ \\
\hline
\end{tabular}

Fonte: Dados da pesquisa (2014)

Para os trabalhos de Belli, Andruchechen, Alberton e Petri (2013), Lima, Gonzaga e Fehr (2013), e Cimini e Silveira (2008) descrevem o processo de implementação em estudo de casos, apresentando analogias nos resultados obtidos.

\section{Metodologia}

O estudo envolve uma pesquisa-ação, devido à participação do pesquisador e dos colaboradores da empresa na elaboração do BSC. De acordo com a metodologia do trabalho cientifico entende-se que pesquisa-ação é:

A pesquisa é considerada como uma pesquisa-ação, pois exige a participação tanto do pesquisador como dos gestores e colaboradores da empresa na elaboração do BSC e para constatação de contribuições ao processo de gestão estratégica (GRAY, 2012).

"[...] pesquisa social com base empírica que é concebida em estreita associação com uma ação ou com a resolução de um problema coletivo e no qual os pesquisadores e os participantes representativos da situação ou do problema estão envolvidos de modo cooperativo ou participativo.”(THIOLLENT, 1998, p. 14).

$\mathrm{Na}$ abordagem de estudo considera-se qualitativa, uma vez que é contextual e interpretativa, além de deter a natureza dos objetivos como descritiva já que descreve e explana os informes contidos no planejamento estratégico de 2012/2013. Conforme Prodanov e Freitas (2013, p. 70), a pesquisa qualitativa envolverá o ambiente natural como fonte direta para coleta de dados e o pesquisador é o instrumento-chave, transformando a pesquisa em descritiva.

No tocante a natureza dos objetivos, é descritiva, por descrever e explanar os dados obtidos do planejamento estratégico e, assim, caracteriza-los e utiliza-los no desenvolvimento do BSC. Segundo Gil (1999, p.70), “a pesquisa descritiva tem como principal objetivo descrever características de determinada população ou fenômeno ou estabelecimento de relações entre as variáveis".

Quanto aos dados obtidos são primários e secundários, por serem obtidos por meio de entrevistas com gestores e colaboradores que fazem parte do processo da 
empresa, desta forma, primários. Ao passo que os dados secundários foram obtidos por relatórios contábeis e no site da empresa, bem como do planejamento estratégico desenvolvido em 2009/2010 pela empresa (GRAY, 2012).

Para elaboração do BSC seguiu-se as seguintes etapas: (i) entrevistas e obtenção dos dados; (ii) estruturação do mapa estratégico e identificação dos objetivos estratégicos e os seus indicadores, etapa elaborada em conjunto pesquisador - gestor; (iii) desenvolvimento do painel do BSC, o qual apresenta as perspectivas; objetivos estratégicos; situação atual; metas; iniciativas para alcançar as metas.. Em seguida, realizou-se a reestruturação do mapa estratégico para a formalização final da visão, dos objetivos e dos indicadores como forma de medir a superação das metas oferecidas. Esta etapa também foi executada em conjunto com a organização (gestores) durantes as entrevistas. Sendo assim, foi possível finalizar o painel de implantação do BSC, apresentando as perspectivas, objetivos estratégicos, situação atual e metas iniciadas pela empresa.

\section{Apresentação da empresa e sua atividade}

Nesta seção, comenta-se sobre as características da empresa no qual a pesquisaação do BSC foi aplicada, sem divulgar dados prejudiciais no cenário empresarial, bem como explanar sobre seu objeto social.

A empresa Sul Brasil Segurança Privada Ltdas ediada no município de Florianópolis, na UF de Santa Catarina, Bairro Centro, cuja natureza jurídica é de sociedade empresarial limitada, caracterizada como empresa de pequeno porte, a qual presta serviços de vigilância e segurança privada para a sociedade.

Os dispositivos legais essenciais e específicos que estabelecem normas de constituição e funcionamentonos serviços de vigilância e segurança privada são a Lei 7.102/1983, alterada pela Lei 8.863/1994 e acréscimos pela Lei 9.017/1995, com a Portaria $n^{\circ}$ 3.233/2012-DG/DPF, alterada pelas Portarias $n^{\circ} 3.258 / 2013$ - DG/DPF, publicada no D.O.U em 14/01/2013 e Portaria $n^{\circ} 3.559$, publicada no D.O.U. em 10/06//2013 entre outrasleis, medidas provisórias e portarias.

Diante disso, o artigo 10 da Lei 7.102/1983 redado pela Lei $n^{\circ}$ 8.863/1994 entende como empresas no ramo de segurança privadas as que exercem a prestação de serviços com a intenção de emanar à vigilância patrimonial das instituições financeiras e 


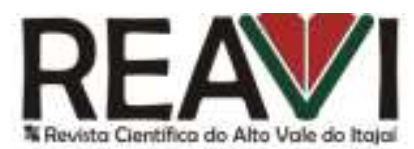

Universidade do Estado de Santa Catarina

Centro de Educação Superior do Alto Vale do Itajaí

de outras instituições, públicas ou privadas e sem fins lucrativos, mas também realizar segurança às pessoas físicas e transportar valores ou outro tipo de carga.

Segundo a Portaria $n^{\circ} 3.233 / 2012$, estas atividades sociais são reguladas, autorizadas e fiscalizadas pelo Departamento de Polícia Federal, consideradas complementares às atividades de segurança pública nos termos da legislação específica. A legislação visa tanto a instituição como seu colaborador,prevendo para o vigilante o uso uniforme obrigatório e devidamente cadastrado a expensas da empresa contratante, portar revólver calibre 32 ou 38 e utilizar cassetete de madeira ou de borracha quando em serviço, prisão especial por ato decorrente do serviço, seguro de vida em grupo obtido pela empresa contratante e além de uma série de requisito para tornar aptos sua empresa e seus funcionários perante o Ministério Públicos e demais órgãos competentes.

Ressalva-se que a Instituição Sul Brasil Segurança Privada Ltda cumpre as imposições acima expostas e nas normas legais, constituindo-se de alvará de funcionamento pela Prefeitura Municipal de Florianópolis, certificado de segurança do Departamento da Policia Federal, como participa de licitações cumpri as obrigações documentais da Lei 8.666/1993, a qual institui normas para licitações e contratos da Administração Pública.

\section{Exposição e Análise dos Resultados}

Nesta seção, são abordados os informes coletados e os resultados obtidos pela pesquisa.

\subsection{Planejamento estratégico}

Segundo os autores, Belli, Andruchechen, Alberton e Petri (2013) a fase do planejamento estratégico é a análise ambiental, que inclui a avaliação de fatores internos e externos que afetam, positiva ou negativamente, a organização.

Neste sentido, a missão seria as atividades prestadas pela empresa. Já a visão é uma projeção futura em que a empresa procura ultrapassar a atual situação dos negócios. Assim, a estratégia é utilizada para extrair informes que deliberaram os planos de ação para atingir os objetivos eleitos.

Observar-se que os informes, no Quadro 2, foram divulgados pela empresa na primeira reunião discutida, os quais tornam-se base para a constituição do BSC. Para 


\section{REAVI}

Universidade do Estado de Santa Catarina

Centro de Educação Superior do Alto Vale do Itajaí

Cimini e Silveira (2008), no processo, o confronto dos conhecimentos entre o empresário e o aplicador enriquece a discussão auxiliando na definição ou revisão da missão, na visão e estratégia que sustentam todo o desdobramento na implantação do BSC.

\begin{tabular}{|l|l|} 
Quadro 2: Planejamento estratégicoempresa Sul Brasil Segurança Privada Ltda \\
\hline Negócio da empresa & Fornecer atendimento de qualidade ao ramo de terceirização de serviços em segurança. \\
\hline Missão & $\begin{array}{l}\text { Assegurar o bem-estar e tranquilidade de milhares de pessoas ao mesmo tempo } \\
\text { em que contribui para uma comunidade mais segura. }\end{array}$ \\
\hline Visão & $\begin{array}{l}\text { Ser referência nos serviços de segurança privadacom foco na satisfação dos } \\
\text { clientes, conquistando a credibilidade e a confiança perante a sociedade nos } \\
\text { serviços. }\end{array}$ \\
\hline Valores & $\begin{array}{l}\text { Ética } \\
\text { Eficiência } \\
\text { Integridade } \\
\text { Respeito } \\
\text { Responsabilidade social } \\
\text { Transparência }\end{array}$ \\
\hline
\end{tabular}

Fonte: Dados da pesquisa (2014)

Conforme expresso pela Equilibrium Assessoria Contábil S/S empresa terceirizada que presta serviços de contabilidade para Sul Brasil Segurança Privada Ltda os pontos fortes exercidos pela entidade consistem em uma imagem positiva perante bancos, uma credibilidade documental, uma boa interação com os clientes e fornecedores. Em contraposição, os pontos fracos seriam o custo de cada contrato, a falta de política regulando o ato de cobrança dos clientes inadimplentes e o controle de faturamento Sapiens versus Excell. Neste aspecto, ao questionar que ameaças e quais os pontos dos seus concorrentes transformar iam-se em ameaças divulga-se:

"Ao se levar em conta o perfil da Sul Brasil, o cenário e sua situação econômico-financeiro consideramos ameaças à articulação política, a organização administrativa, a forte dependência dos poderes públicos e a falta de visão holística do corpo gerencial e coordenadores.Todavia, a análise desses pontos fracos e ameaças dão oportunidades para melhorar a organização"Elias Oliveira Amaral, contador e responsável legal da Equilibrium Assessoria Contábil S/S.

Como exemplo de oportunidades citado a cima tem-se a instalação de software B.I., o departamento comercial entrar em acordo com DEFAT para acerto das datas de pagamento nos futuros contratos, a aplicação de algumas ferramentas organizacionais da ISO 9000 para organização interna (PS/PO/5W1H) e controle ERP. 
Diante do quadro anterior tem-se a possibilidade de estruturar o mapa estratégico que de acordo com Kaplan e Norton (2000, página 81) seria “[...] uma arquitetura genérica para a descrição da estratégia." Sendo assim para os autores, o mapa estratégico auxilia as empresas a construírem alicerces ao sistema gerencial na implantação estratégica de forma integrada e sistemática. Portanto, na figura 2 abaixo evidencia as estratégicas e as expectativas referentes à empresa.

\section{Figura 2: Mapa estratégico da empresa Sul Brasil Segurança Privada Ltda}

Missão: Assegurar o bem-estar e tranquilidade de milhares de pessoas ao mesmo tempo em que contribui para uma comunidade mais segura.

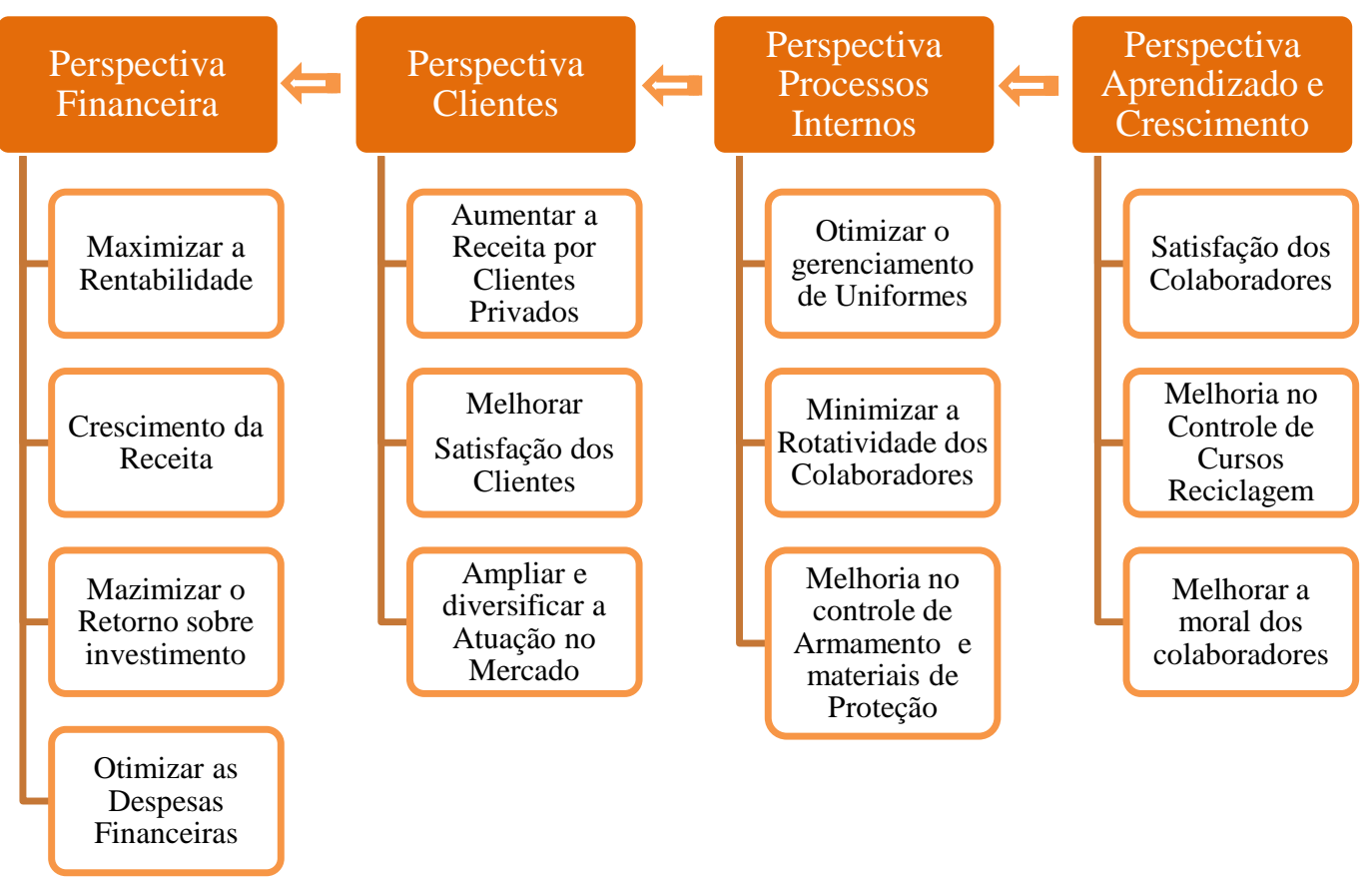

Fonte: Dados da pesquisa (2014)

Nota-se que após serem identificados no mapa estratégico os principais objetivos da entidade, este servirá de bússola para orientar as ações a serem realizadas pela entidade. Segundo Kaplan e Norton (1997), a partir deste aspecto têm-se a necessidade de mensurar indicadores financeiros e não-financeiros que traduzam o desempenho e as iniciativas necessárias para a realização dos objetivos estratégicos. Portanto para os autores, cada indicador se alinha como parte integrante de uma cadeia lógica de causa e efeito, relacionados aos resultados desejados da estratégia com os vetores que levarão a 


\section{REAVI}

Universidade do Estado de Santa Catarina

Centro de Educação Superior do Alto Vale do Itajaí

essas decorrências, uma vez que indicadores isolados são limitantes ao descrever a criação de valor da entidade.

No quadro 3, as quatros perspectivas contrabalançam finalidades de curto e longo prazo, tendo cada perspectiva arrolada entre si, ou seja, estabelecendo uma relação de causa e efeito. Segundo as entrevistas com os gerentes, o BSC mostrou-se flexível a diversas circunstâncias. Estas entrevistas na primeira etapa de constituição do BSC foram de suma importância na definição da estratégia, uma vez que a construção dos objetivos estratégicos retém tempo e, ainda há uma cultura de se ater aos aspectos pontuais e operacionais.

No que tange a discussão das perspectivas, a empresa solicitou atenção especial na perspectiva de clientes, já que esta corrobora o objetivo estratégico final de realizar serviços de segurança, assegurando a satisfação dos clientes, no qual afluem os resultados de outrem objetivos, devido à relação de causa e efeito.

Observa-se a carteira de clientes da empresa é composta, aproximadamente, em 99\% de clientes no setor público, pretende para os exercícios futuros aumentar à captação de novos clientes no setor privado, angariando através do seu departamento comercial, por visitas as empresas e residenciais, oferecendo um serviço de qualidade e preço atrativo, com prazo de iniciação imediato.

\section{Quadro 3: Balanced Scorecard da empresa Sul Brasil Segurança Privada Ltda}

\begin{tabular}{|c|c|c|c|c|c|c|}
\hline Perspectivas & Objetivos Estratégicos & Indicadores & SQ & Meta & Iniciativa & Responsáveis \\
\hline \multirow{4}{*}{ 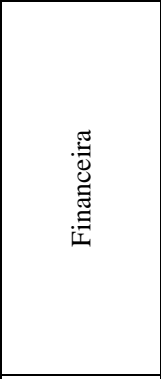 } & \multirow{2}{*}{ Maximizar a rentabilidade } & $\begin{array}{l}\text { Rentabilidade (Lucro } \\
\text { líquido/Patrimônio líquido) }\end{array}$ & $29 \%$ & $30 \%$ & \multirow{4}{*}{$\begin{array}{l}\text { Revisar as formas } \\
\text { de pagamentos com } \\
\text { inadimplência; } \\
\text { Identificar o } \\
\text { cumprimento do } \\
\text { prazo das } \\
\text { obrigações para } \\
\text { reduzir as despesas } \\
\text { financeiras; }\end{array}$} & Financeiro \\
\hline & & Inadimplência/Lucro líquido & $-7,5 \%$ & $-4,5 \%$ & & Financeiro \\
\hline & Crescimento da Receita & $\begin{array}{l}\text { (Total de venda do ano- Totalde } \\
\text { venda do ano anterior)/Totalde } \\
\text { venda do ano anterior }\end{array}$ & $8,70 \%$ & $9 \%$ & & Financeiro \\
\hline & $\begin{array}{c}\text { Aperfeiçoar despesas } \\
\text { financeiras } \\
\end{array}$ & $\begin{array}{l}\text { Índice cobertura despesas } \\
\text { financeiras (EBTIDA/Despesas } \\
\text { financeiras) }\end{array}$ & 7,71 & 5,6 & & Financeiro \\
\hline \multirow{6}{*}{ 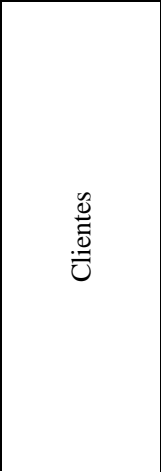 } & $\begin{array}{l}\text { Aumentar a receita por } \\
\text { clientes privados }\end{array}$ & $\begin{array}{l}\text { Lucro líquido por clientes } \\
\text { privados - despesas necessárias } \\
\text { para ter esses clientes }\end{array}$ & - & - & $\begin{array}{l}\text { Verificar os prazos } \\
\text { para cumprir os } \\
\text { cronogramas de }\end{array}$ & Comercial \\
\hline & \multirow{3}{*}{$\begin{array}{c}\text { Melhorar a satisfação dos } \\
\text { clientes }\end{array}$} & $\begin{array}{l}\% \text { de clientes que se declaram } \\
\text { satisfeitos }\end{array}$ & 0 & 0 & \multirow{5}{*}{$\begin{array}{l}\text { serviços; Conterır } \\
\text { falhas na prestação } \\
\text { de serviços passados } \\
\text { para minimizar os } \\
\text { futuros; }\end{array}$} & Comercial \\
\hline & & $\begin{array}{l}\text { Números de prazos não } \\
\text { atendidos }\end{array}$ & - & - & & Comercial \\
\hline & & $\begin{array}{l}\text { Números de reclamações } \\
\text { (ouvidoria e registrados por } \\
\text { escrito) }\end{array}$ & 6 & 2 & & Comercial \\
\hline & \multirow{2}{*}{$\begin{array}{l}\text { Ampliar e diversificar a } \\
\text { atuação do mercado }\end{array}$} & $\begin{array}{l}\text { Número de indicados por } \\
\text { clientes }\end{array}$ & 0 & 0 & & Comercial \\
\hline & & $\begin{array}{l}\text { Percentual de vendas totais na } \\
\text { área de atuação }\end{array}$ & - & - & & Comercial \\
\hline
\end{tabular}




\section{REAVI}

Universidade do Estado de Santa Catarina

Centro de Educação Superior do Alto Vale do Itajaí

\begin{tabular}{|c|c|c|c|c|c|c|}
\hline \multirow{6}{*}{ 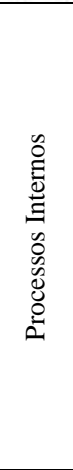 } & \multirow{2}{*}{$\begin{array}{c}\text { Aperfeiçoar o gerenciamento } \\
\text { de uniformes }\end{array}$} & $\begin{array}{l}\text { * Número de uniformes retirados } \\
\text { por colaboradores ativos }\end{array}$ & 158 & 158 & \multirow{6}{*}{$\begin{array}{l}\text { Evento de } \\
\text { integração; } \\
\text { Construir um plano } \\
\text { de carreira; } \\
\text { Implantação de } \\
\text { controle para reduzir } \\
\text { o desperdício e } \\
\text { manutenção de } \\
\text { matérias; }\end{array}$} & Pessoal \\
\hline & & $\begin{array}{l}\% \text { de reclamação por clientes } \\
\text { devido a mau uso de uniformes }\end{array}$ & 4 & 1 & & Pessoal \\
\hline & $\begin{array}{c}\text { Minimizar a Rotatividade dos } \\
\text { Colaboradores }\end{array}$ & Turnover & $29,74 \%$ & $27 \%$ & & Pessoal \\
\hline & \multirow{2}{*}{$\begin{array}{c}\text { Melhoria no controle de } \\
\text { Armamento e Materiais de } \\
\text { Proteção }\end{array}$} & **Manutenção de Armamentos & $98 \%$ & $99 \%$ & & Operacional \\
\hline & & $\begin{array}{l}* * * \text { Número de matérias de } \\
\text { proteção obsoleta }\end{array}$ & 145 & 145 & & Operacional \\
\hline & Facilitar comunicação & $\begin{array}{l}\text { Reunião de integração setorial, } \\
\text { visando os objetivos, os } \\
\text { processos e asequipes }\end{array}$ & 0 & 0 & & Pessoal \\
\hline \multirow{5}{*}{ 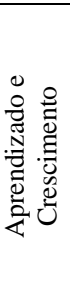 } & Satisfação dos Colaboradores & Índice de demissões voluntárias & $3,05 \%$ & $2 \%$ & \multirow{5}{*}{$\begin{array}{l}\text { Definir um } \\
\text { planejamento de } \\
\text { orçamento para } \\
\text { capacitação de } \\
\text { pessoal/área; } \\
\text { Incentivar por } \\
\text { remuneração } \\
\text { variável os } \\
\text { colaboradores; }\end{array}$} & Pessoal \\
\hline & \multirow{2}{*}{$\begin{array}{l}\text { Melhoria no Controle de } \\
\text { Cursos Reciclagem }\end{array}$} & $\begin{array}{l}\text { Média de horas de treinamento } \\
\text { por colaboradores }\end{array}$ & $125 \mathrm{~h}$ & $150 \mathrm{~h}$ & & Pessoal \\
\hline & & $\begin{array}{l}* * * * \% \text { de colaboradores } \\
\text { habilitados }\end{array}$ & $97 \%$ & $99 \%$ & & Pessoal \\
\hline & \multirow{2}{*}{$\begin{array}{l}\text { Melhorar a moral dos } \\
\text { colaboradores }\end{array}$} & $\begin{array}{l}\text { Número de indicação de novos } \\
\text { clientes por colaboradores }\end{array}$ & 0 & 0 & & Pessoal \\
\hline & & Realizar recrutamento interno & 0 & 0 & & Pessoal \\
\hline
\end{tabular}

* De acordo com as normas estabelecidas pela a empresa cada colaborador contratado recebe um uniforme contendo duas camisas e uma calça, sendo que a cada 6 meses renova-se o uniforme composto por uma camisa e uma calça. Também, obtêmse, a cada 1ano, uma boina, uma gravata e um sapato por colaborador.

**As armas são registradas no GESP e na execução do serviço ficam vinculadas aos postos de serviços.

***Consideram-se materiais de proteção coldres e cacetes, tendo cada colete um prazo de cinco anos para substituição.

****Tem-se como colaborador habilitado àquele que possui o curso de reciclagem em dia, obtendo a cada dois anos sua renovação.

- Informações não divulgadas pela empresa.

\section{Fonte: Dados da pesquisa (2014)}

O custo para atrair novos clientes será o investimento em portfólios, propaganda e visitas com gastos em combustíveis, locação de veículos, tendoos demais custos do departamento comercial já incluso na taxa administrativa na formação do preço deserviço de vigilância, que é composto da seguinte forma: montante A (remuneração, adicionais, indenizações e encargos sociais) e montante B (insumos de mão-de-obra, demais componentes e tributos).

Ressalta-se que há um projeto de sediar uma filial noRio Grande do Sul, buscando ampliar sua participação no mercado privado.

\subsection{Análise dos Resultados}

A elaboração do BSC tomou como base o planejamento estratégico desenvolvido pela empresa no de 2011 para os anos 2012/2013, ajustado em função de alterações do ambiente. Tendo por base essas informações, utilizaram-se as perspectivas apontadas por Kaplan e Norton (1992), pois se adequavam ao planejamento estratégico da empresa. A partir disso, por meio de entrevistas, elaboraram-se os objetivos 


\section{REAVI}

Universidade do Estado de Santa Catarina

Centro de Educação Superior do Alto Vale do Itajaí

estratégicos e indicadores, além da mensuração dos objetivos e estabelecimento de metas, como pode se observar no Quadro 3.

Desta forma, o mapa estratégico contém 13 objetivos. A partir deste, elaborou-se o painel do BSC, apresentando 16 indicadores estratégicos alinhados com as iniciativas, passíveis de mensuração e, assim, monitorados, para que a gestão estratégica da empresa possa ser facilitada e passível de acompanhamento por tais indicadores. A empresa apresenta uma meta em nível de excelência, isto é, seus indicadores apontam que determinados itens a entidade já ultrapassou a meta. Porém, os demais itens encontram-se em nível de mercado ou competitivo; comprometedor ou sobrevivência, para os indicadores que se encontram nesse último grupo a empresa deve se atentar visando agir para que as metas sejam alcançadas por meio das iniciativas apresentadas, a fim de minimizar possíveis problemas que possam acarretar a viabilidade da empresa e a até mesmo a sua existência.

Assim, é possível observar, tanto no mapa ou painel e, até mesmo, no gráfico, que as perspectivas utilizadas para elaboração do BSC foram as mesmas apresentadas por Kaplan e Norton (1992). Contudo, ressalta-se que, além de ser as mesmas apresentadas no trabalho citado acima, foram as mesmas utilizadas nos trabalhos de Drouvot; Gomes.(2014); Lima, Gonzaga e Fehr (2013); Belli, Andruchechen, Albertone, Petri (2013); Bernardi, Silva e Batocchio (2012) e Cimini e Silveira (2008).

Percebeu-se uma similaridade referente aos indicadores utilizados nos trabalhos de Lima et al. (2011); Belli, Andruchechen, Albertone, Petri (2013); Bernardi, Silva e Batocchio (2012) e Cimini e Silveira (2008). Os estudos citados, utilizaram como medida de desempenho financeiro o retorno sobre o patrimônio líquido, bem como neste estudo. Da mesma forma, notaram-se algumas similaridades em outros indicadores, por exemplo, perspectiva cliente.

\section{Considerações finais}

Nas empresas atuais, a contabilidade esta num complexo processo de atribuição de poder, no qual as ferramentas de contabilidade gerencial não são apenas técnicas para averiguar a situação da empresa, mas sim uma ferramenta de amadurecimento da missão e visão estratégica.

Na elaboração do BSC, houve um alinhamento entre os objetivos estratégicos e os aspectos operacionais emergentes, principalmente na perspectiva de clientes. Sendo 


\section{REAVI}

Universidade do Estado de Santa Catarina

Centro de Educação Superior do Alto Vale do Itajaí

assim, os gerentes consideraram o BSC flexível e realista, uma vez que pode ser constituído respeitando as características particulares da empresa e a definição dos indicadores estratégicos procura medir de forma autêntica os objetivos estratégicos.

O processo do BSC contribuiu para integrar os colaboradores da empresa quanto à estratégica da organização de forma praticável, unificando os departamentos entre si através da disposição dos indicadores de desempenho. Além disso, constam-se na base teórica algumas similaridades na contribuição do BSC e na forma de mensuração dos indicadores.

Ressalva-se que as considerações finais obtidas tanto neste estudo quanto nas pesquisas referentes ao Quadro 1 resultaram como contribuições positivas a elaboração do BSC, uma vez que a constituição do painel considerou as particularidades de cada entidade.

Quanto à limitação da pesquisa, apenas utilizou-se informações disponíveis da performance atualizada, não efetuando medições ou pesquisa relacionadas à satisfação dos clientes, como exemplo.

\section{Referências}

SOARES, Bruna Braga; SILVA, Itacir Alves da. Indicadores Financeiros do Balanced Scorecard. Revista de Contabilidade, Ciência da Gestão e Finanças, v. 1, n. 1, 2013. Disponível em: <http://ojs.fsg.br/index.php/rccgf/article/view/158> Acesso em: 05 nov. 2014.

VIEIRA, Rafael Tadeu. A Contribuição do Balanced Scorecard na Gestão Estratégica de um Escritório de Contabilidade. Revista Pensar Contábil, v. 16, n. 60, p. 4-13, 2014.Disponível em: <http://www.atena.org.br/revista/ojs-2.2.308/index.php/pensarcontabil/article/view/2194/1925>Acesso em: 05 nov. 2014.

PRODANOV, Cleber Cristiano; FREITAS, Ernani Cesar de. Metodologia do trabalho científico:métodos e técnicas de pesquisa e do trabalho acadêmico. 2. ed. Novo Hamburgo/RS: Feevale, 2013. Disponível em:< http://migre.me/eqVxf >Acesso em: 17 nov 2014.

BERNARDI, Talita; SILVA, Iris Bento da; BATOCCHIO, Antonio. Roteiro para implantação de Balanced Scorecard: estudo de caso em pequena empresa. Revista de $\begin{array}{lllll}\text { Ciência } \quad \text { S } & \text { Tecnologia. v.17, } & \text { n. 33, 2012.Disponível }\end{array}$ em:<https://www.metodista.br/revistas/revistasunimep/index.php/cienciatecnologia/article/view/1044>Acesso em: 05 nov 2014.

LIMA, Lívia Carolina de Matos; GONZAGA, Rosimeire Pimentel; FEHR, Lara Cristina Francisco de Almeida. Balanced Scorecard: é possível a sua implantação e 
uso em uma construtora de pequeno porte? XX Congresso Brasileiro de Custos Uberlândia, MG, Brasil, 18 a 20 de novembro de 2013. Disponível em <http://anaiscbc.emnuves.com.br/anais/article/download/165/165>Acesso em: 20 nov 2014.

ANDRUCHECHEN, Jean Roberto; BELLI, Ana Paula; PETRI, Sérgio Murilo; ALBERTON, Luiz. Proposta de implementação do planejamento estratégico e balancedscorecard: um estudo em uma microempresa de manufatura. Revista de estudos contábeis, Londrina, v. 4, n. 7, p. 57-76, jul./dez. 2013. Disponível em: <http://www.uel.br/revistas/uel/index.php/rec/article/view/16305> Acesso em: 20 nov 2014.

LIMA, Cristiano de et al. Indicadores de Gestão: Um Estudo sob a ótica do Balanced Scorecard-BSC. Revista Eletrônica Saber Contábil, v. 1, n. 2, p. 107-120, 2012. Disponívelem:<http://revista.ulbrajp.edu.br/ojs/index.php/contabeis/article/view/1405/3 06>Acesso em: 05 nov2014.

RIVA, Adriano Luiz; DE LIMA FEDATO, Geovana Alves. Geração de Informações Contábeis Gerenciais Utilizando a Metodologia do Balanced Scorecard: Um Estudo de Caso. Contabilidade \& Amazônia, v. 2, n. 1, p. 30-43, 2012. Disponível em: <http://www.contabilidadeamazonia.com.br/artigos/artigo_46artigo_03.pdf>Acesso em: 05 nov 2014.

GASPARETTO, Alex Sandro et al. Implantação do Balanced Scorecard: estudo de caso em empresa de consultoria. Revista de Contabilidade do Mestrado em Ciências Contábeis da UERJ, v. 12, n. $1, \quad 2010 . \quad$ Disponível em:<http://www.atena.org.br/revista/ojs-2.2.3-

08/index.php/UERJ/article/view/644/640> Acesso em: 05 nov 2014.

CIMINO, Júlio Cezar da Silva; SILVEIRA, Cristiane de Sales. Implantação do Balanced Scorecard (BSC) em pequenas empresas. XV Congresso Brasileiro de Custos - Curitiba, PR, Brasil, 12 a 14 de novembro de 2008. Disponível em:〈http://anaiscbc.emnuvens.com.br/anais/article/viewFile/1172/1172> Acesso em: 18 nov 2014.

HERRERO FILHO, Emílio. Balancedscorecard e a gestão estratégica: uma abordagem prática. 10. ed. Rio de Janeiro: Elsevier, 2005.

Gil, A. C. (1999). Métodos e técnicas de pesquisa social. São Paulo: Atlas.

GRAY, D. E. (2012). Pesquisa no mundo real. Tradução de Roberto Cataldo Costa, 2.

_, Robert S; __, David P. Kaplan e Norton na Prática. 10.ed. Rio de Janeiro: Elsevier, 2004.

KLAPAN, Robert S.; NORTON, David P. Organização Orientada para a Estratégia: como as empresas que adotam o balancedscorecard prosperam no novo ambiente de negócios. 20.ed. Rio de Janeiro: Elsevier, 2000. 


\section{REAVI}

Universidade do Estado de Santa Catarina

Centro de Educação Superior do Alto Vale do Itajaí

THIOLLENT, M. Metodologia da pesquisa-ação. 8. ed. São Paulo: Cortez, 1998.

KLAPAN, Robert S.; NORTON, David P. A estratégica em ação:balancedscoredcard. 23. ed. Rio de Janeiro: Campus, 1997.

Mudanças no supersimples: o que o dono de pequeno negócio deve saber. Disponível em: $\quad$ http://www.sebrae.com.br/sites/PortalSebrae/artigos/Mudan\%C3\%A7as-noSupersimples:-o-que-o-dono-de-pequeno-neg\%C3\%B3cio-deve-saber> Acesso em: 20 fev 2015.

Supersimples começa valer em 2015 com novo regime de tributação. Disponível em: $<$ http://g1.globo.com/economia/pme/noticia/2014/11/supersimples-comeca-valer-em2015-com-novo-regime-de-tributacao.html> Acesso em: 20 fev 2015. 